\title{
PENGARUH MEDIA PEMBELAJARAN BERBASIS TIK DAN SIKAP INOVASI TERHADAP HASIL BELAJAR PERENCANAAN PEMBELAJARAN DENGAN HOTS
}

\author{
R. Mursid ${ }^{1}$, Abdul hasan Saragih ${ }^{2}$, Naeklan Simbolon ${ }^{3}$ \\ Teknologi Pendidikan Pascasarjana Universitas Negeri Medan \\ mursid.tp@gmail.com ${ }^{1}$,ahasansaragih@gmail.com ${ }^{2}$
}

\begin{abstract}
Abstrak: Penelitian ini bertujuan untuk mengetahui apakah hasil belajar perencanaan pengajaran dengan HOTS lebih tinggi bila diajar dengan menggunakan web online dan dengan Komputer offline, perencanaan pengajaran dengan HOTS mahasiswa lebih tinggi bila memiliki sikap inovatif positif lebih tinggi dibandingkan sikap inovatif negatif dan untuk mengetahui interaksi antara media pembelajaran berbasis TIK dengan sikap inovatif mahasiswa. Penelitian ini dilaksanakan pada mahasiswa yang mengambil matakuliah perencanaan pembelajaran purposive random sampling. Metode penelitian adalah kuasi eksperimen dengan desain faktorial $2 \times 2$. Uji statistik yang digunakan adalah statistik deskriptif untuk menyajikan data dan dilanjutkan dengan statistik inferensial dengan menggunakan ANAVA dua jalur dengan taraf signifikan $\alpha=0,05$ yang dilanjutkan dengan uji Scheffe. Hasil penelitian ini menunjukkan bahwa; (1) hasil belajar perencanaan pengajaran dengan media pembelajaran berbasis web online lebih tinggi dibandingkan dengan TIK offline; (2) Hasil belajar perencanaan pengajaran yang memiliki sikap inovatif positif lebih tinggi daripada sikap inovatif negatif; dan terdapat interaksi antara media pembelajaran berbasis TIK dengan sikap inovatif terhadap hasil belajar perencanaan pengajaran.
\end{abstract}

Kata Kunci: media pembelajaran berbasis TIK, sikap inovasi, perencanaan pembelajaran HOTS

Abstract: This study aims to determine whether the results of learning planning of teaching with HOTS higher when taught by using online web and with offline computer, teaching planning with HOTS students higher when having positive innovative attitude is higher than negative innovative attitude and to know the interaction between learning media based on ICT with students' innovative attitude. This research is conducted on students who take course of purposive random sampling learning. The research method is quasi experiment with $2 \times 2$ factorial design. Statistical test used is descriptive statistic to present the data and continued with inferential statistic by using two way ANOVA with significant level $\alpha=0,05$ followed by Scheffe test. The results of this study indicate that; (1) the learning result of teaching planning with online web-based learning media is higher than offline ICT; (2) Learning planning outcomes that have positive innovative attitudes are higher than negative innovative attitudes; and there is an interaction between ICT-based learning media with innovative attitudes toward learning learning planning outcomes.

Keywords: ICT-based learning media, innovation attitude, HOTS learning plan

\section{PENDAHULUAN}

Dalam era informasi, kecanggihan teknologi informasi dan komunikasi telah memungkinkan terjadinya pertukaran informasi yang cepat tanpa terhambat oleh batas ruang dan waktu (Dryden \& Voss, 1999). Berbeda dengan era agraris dan industri, kemajuan suatu bangsa dalam era informasi/ global sangat tergantung pada kemampuan masyarakatnya dalam memanfaatkan pengetahuan untuk meningkatkan produktifitas. Karakteristik masyarakat seperti ini dikenal dengan istilah masyarakat berbasis pengetahuan (knowledge- based society). Orang yang menguasai pengetahuan akan mampu bersaing dalam era global. Oleh karena itu, setiap negara berlomba untuk mengintegrasikan ICT dalam semua aspek kehidupan berbangsa dan bernegara, untuk membangun dan membudayakan masyarakat berbasis pengetahuan agar dapat bersaing dalam era global.

Dale (1969) menjelaskan bahwa untuk menjamin bahwa sumber belajar yang digunakan baik atau cocok untuk keperluan sebagaimana dikatakan di atas harus memenuhi tiga persyaratan sebagai berikut: (1) harus dapat 
tersedia dengan cepat; (2) harus dapat memungkinkan siswa untuk memacu diri sendiri; (3) harus bersifat individual, memenuhi kebutuhan siswa belajar mandiri. Sedangkan manifestasi fisik dari teknologi perangkat keras, perangkat lunak dan bahan pembelajaran menurut Dale (1969) dapat dikategorikan dalam empat jenis teknologi yaitu teknologi cetak, teknologi audio-visual, teknologi komputer, dan teknologi terpadu.

Di dalam pembelajaran, kedudukan media menurut Rusman (2009:144) adalah sebagai sumber belajar yang dapat berfungsi sebagai: (1) Total Teaching, sumber belajar atau media digunakan secara penuh dari awal hingga akhir proses pembelajaran, fungsi guru hanya fasilitator dalam pembelajaran di kelas ataupun di luar kelas; (2) Major Resources, sumber belajar atau media yang digunakan sebagai sumber belajar utama/dominan dalam proses pembelajaran. Posisi guru hanya memperjelas sumber atau media yang digunakan; dan (3) Suplement View, posisi sumber dan media pembelajaran hanya sebagai pelengkap dalam proses pembelajaran, dimana posisi guru lebih banyak sebagai sumber informasi dan posisi sumber/media pembelajaran hanya sebagai pelengkap saja.

Menurut Gerlach \& Ely (Arsyad, 2009: 12-14) ada tiga ciri media yang merupakan petunjuk mengapa media digunakan dan apaapa saja yang dapat dilakukan oleh media yang mungkin guru tidak mampu (atau kurang efisien) melakukannya, yaitu fikstif, manipulatif, dan distributif. Ciri fiksatif menggambarkan kemampuan media merekam, menyimpan, melestarikan, dan merekonstruksi suatu peristiwa atau objek. Objek dapat diurut dan disusun kembali dengan media seperti: fotografi, video tape, audio tape, disket komputer, dan film.

Secara umum, Lucas (2000) menguraikan definisi teknologi informasi, yang dijelaskan sebagai berikut: "Teknologi informasi adalah segala bentuk teknologi yang diterapkan untuk memproses dan mengirimkan informasi dalam bentuk elektronis, mikro komputer, komputer mainframe, pembaca barcode, perangkat lunak pemproses transaksi, perangkat lembar kerja (worksheet), peralatan komunikasi dan jaringan merupakan contoh teknologi informasi".

Sedangkan menurut Wardiana (2000:34) teknologi informasi adalah suatu teknologi yang digunakan untuk mengolah data, termasuk memproses, mendapatkan, menyusun, menyimpan, memanipulasi, dan berbagai cara untuk menghasilkan informasi yang berkualitas, yaitu informasi yang relevan, akurat, dan tepat waktu, yang digunakan untuk keperluan pribadi, bisnis, dan pemerintahan yang merupakan aspek strategis untuk pengambilan keputusan.

Sedangkan Munir (2008) membagi teknologi informasi atas 6 (enam) bagian, yaitu: teknologi masukan (input technology), teknologi keluaran (output technology), teknologi perangkat lunak (software technology), teknologi penyimpanan (storage technology), dan mesin pemrosesan (processing machine) atau CPU. Sedangkan teknologi komunikasi adalah perangkat-perangkat teknologi yang terdiri dari hardware, software, proses dan sistem, yang digunakan untuk membantu proses komunikasi yang bertujuan agar komunikasi berhasil (komunikatif).

Setelah beberapa penjelasan, dapat dikaitkan antara teknologi informasi dan teknologi komunikasi. Teknologi informasi menekankan pada pelaksanaan dan pemrosesan data seperti mentransmisikan, menyimpan, mengambil, memanipulasi atau menampilkan data dengan menggunakan perangkat-perangkat teknologi elektronik terutama komputer, sedangkan teknologi komunikasi menekankan pada penggunaan perangkat teknologi elektronik dan lebih menekankan pada aspek ketercapaian tujuan dalam proses komunikasi, sehingga data dan informasi yang diolah dengan teknologi informasi harus memenuhi kritera komunikasi yang efektif. Lebih jelasnya, keterkaitan antara teknologi informasi dan teknologi komunikasi adalah teknologi informasi lebih kepada sistem pengolahan informasi dan teknologi komunikasi berfungsi untuk mengirimkan informasi (information delivery). Oleh karena itu, teknologi informasi dan komunikasi (TIK) tidak identik dengan komputer tetapi juga dengan segala sesuatu yang berupa software dan hardware yang dapat membantu manusia.

Pembelajaran berbasis komputer merupakan program pembelajaran dengan menggunakan software komputer (CD pembelajaran) berupa program komputer yang berisi tentang muatan pembelajara meliputi: judul, tujuan, materi pembelajaran, dan evaluasi pembelajaran. Hal tersebut sejalan dengan apa yang dikemukakan oleh Heinich, Molenda, dan James D. Russel (1985:226) yang menyatakan bahwa: "Computer system can delivery 
instruction by allowing them to interact with the lesson programmed into the system; this is refered to computer based instruction". Sistem komputer dapat menyampaikan pembelajaran secara individual dan langsung kepada para siswa dengan cara berinteraksi dengan mata pelajaran yang diprogramkan ke dalam sistem komputer, inilah yang disebut dengan media pembelajaran berbasis komputer.

World wide web atau disebut web atau $w w w$, merupakan multimedia yang berisi berbagai informasi yang bisa diakses melalui internet di mana dokumen-dokumen hypermedia (file komputer) disimpan dan dapat diambil melalui alamat yang telah ditata dan ditentukan dengan cara unik. Web bukan hanya sekedar menangani materi berbentuk teks, tetapi mampu menyimpan dan mengambil hypermedia - multimedia yang terdiri dari teks, grafik, audio, dan video. Lebih lanjut diungkapkan, bahwa $w w w$ merupakan kumpulan komputer yang bertindak sebagai server yang menyediakan berbagai isi informasi (content server), pada $w w w$ ini terdapat dokumen-dokumen dalam format tertentu yang memungkinkan dokumen tersebut dilihat sebagai teks, grafik, audio, dan juga dihubungkan dengan dokumen lainnya pada web (McLeod dan Schell, 2007:71-72). Selain bersifat elektronik dan dapat diakses kapan dan di mana saja serta oleh siapa saja, menurut Shelly (2007:67) web juga merupakan layanan yang sangat banyak dimanfaatkan dalam internet karena terdiri atas kumpulan dokumen elektronik dari seluruh negara. Web menyediakan pendekatan-pendekatan inovatif dalam menyajikan pelatihan atau pembelajaran jarak jauh. Menurut Hall (2003:1), WBI (web based instruction) didefinisikan sebagai sebuah program pembelajaran berbasis hypermedia yang memanfaatkan berbagai fitur dan sumber $w w w$ (world wide web) untuk menciptakan lingkungan belajar yang suportif dan bermakna. Sementara itu, menurut Vaughan world wide web merupakan sebuah sistem informasi hypermedia kolaboratif terdistribusi. Sistem yang dirancang sebagai sebuah protokol untuk menghubungkan berbagai keanekaragaman dokumen yang ditempatkan pada komputer mana pun di dalam internet (Vaughan, 2006:286). Dari pendapat para ahli dapat disimpulkan, bahwa yang dimaksud dengan web dalam penelitian pengembangan ini merupakan suatu multimedia yang memuat berbagai dokumen dengan berbagai karakter (teks, audio, visual, animasi) yang terhubung oleh jaringan internet dan dapat diakses secara online.

Menurut AECT (1977) dalam Sadiman dan kawan-kawan (2007:19) media atau bahan adalah perangkat lunak (software) berisi pesan atau informasi pendidikan yang biasanya disajikan dengan mempergunakan peralatan. Peralatan atau perangkat keras (hardware) merupakan sarana untuk dapat menampilkan pesan yang terkandung pada media tersebut. Apapun batasan yang diberikan, ada persamaan diantara batasan tersebut yaitu bahwa media adalah segala sesuatu yang dapat digunakan untuk menyalurkan pesan dari pengirim ke penerima sehingga dapat merangsang pikiran, perasaan, perhatian dan minat serta perhatian siswa sedemikian rupa sehingga terjadi proses pembelajaran. Sedangkan Romiszowski (1993) mengatakan media pembelajaran adalah: ".....as the carries of massages, from some transmitting source (which may be a human being or an intimate object), to the receiver of the massage (which is our case is the learner)."

Adapun strategi yang digunakan dalam media pembelajaran ini adalah blended learning. Secara etimologi istilah Blended Learning terdiri dari dua kata yaitu Blended dan Learning. Kata blend berarti "campuran, bersama untuk meningkatkan kualitas agar bertambah baik" (Collins Dictionary), atau formula suatu penyelarasan kombinasi atau perpaduan (Heinze and Procter, 2006: 236). Sedangkan learning memiliki makna umum yakni belajar. Dengan demikian, sepintas mengandung makna pola pembelajaran yang mengandung unsur pencampuran, atau penggabungan antara satu pola dengan pola yang lainnya. Apa yang dicampurkan? Elenena Mosa (2006) menyampaikan bahwa yang dicampurkan adalah dua unsur utama, yakni pembelajaran di kelas (classroom lesson) dengan online learning. 


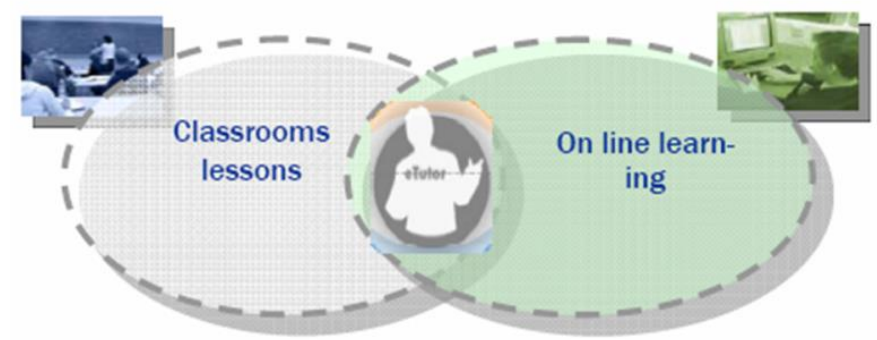

Gambar 1: Proses Belajar Blended Learning

Selain blended learning ada istilah lain yang sering digunakan di antaranya blended learning dan hybrid learning. Istilah yang disebutkan tadi mengandung arti yang sama yaitu perpaduan, percampuran atau kombinasi pembelajaran. Supaya tidak membingungkan masalah tersebut pernah dijelaskan oleh Mainnen (2008) yang menyebutkan "Blended learning mempunyai beberapa alternatif nama yaitu mixed learning, hybrid learning, Blended Blended e-learning dan melted learning (bahasa Finlandia)." Karena model pembelajaran campuran ini lebih banyak menggunakan blended e-learning pada perkuliahan dari pada tatap muka atau residensial dan tutorial kunjung, maka penulis menggunakan istilah Blended Blended $e$ learning. Selain itu Heinze $(2008 ; 14)$ juga berpendapat "A better term for 'blended learning' is 'blended blended e-learning'."

Pembelajaran perencanaan pengajaran dengan HOTS berbasis web biasanya menyangkut interaktivitas antara yang belajar dan sistem. Untuk menciptakan sistem belajar yang interaktif kita dapat memisahkan proses desain ke dalam tiga elemen atau bagian, yaitu desain informasi, desain interaksi dan desain presentasi (Kristof \& Satran,1995)

Proses pembelajaran pada prodi pendidikan teknik mesin pada matakuliah Perencanaan Pembelajaran dengan HOTS dilihat dari ketuntasan belajar dan hasil belajar mahasiswa, tidak terdapat indikasi masalah yang berarti seperti pada mata kuliah-mata kuliah di rumpun pendidikan. Namun demikian, pada proses pembelajaran yang berlangsung di kelas hingga saat ini, masih berpusat pada dosen atau sering disebut juga teacher centered atau dikenal dengan pendekatan tradisional (Utami, et al : 2011).

Berkaitan dengan hal tersebut, Thomas \& Litowitz (1986: 1) menyatakan bahwa fokus utama dalam semua area pendidikan saat ini adalah dampak pendidikan pada kemampuan mahasiswa dalam menggunakan HOTS. Pemahaman dan peningkatan pengetahuan, kemampuan kognitif, dan penempatan yang menuntun, mengatur, dan bentuk tindakan efektif di tempat kerja, keluarga, dan masyarakat adalah masalah yang signifikan bagi pendidikan abad XXI. Hal ini menunjukkan bahwa HOTS menjadi satu hal yang sangat penting yang harus diterapkan dan ditingkatkan di perguruan tinggi.

Mencermati uraian di atas, maka dapat dikatakan bahwa HOTS merupakan keterampilan penting untuk keberhasilan studi, bekerja, dan hidup di era informasi dan teknologi abad ke XXI. HOTS dan komponennya ini dapat dikembangkan dan digunakan dengan baik ketika mempelajari suatu pengetahuan. Oleh karena itu, proses pembelajaran di perguruan tinggi perlu menekankan pada pengembangan HOTS mahasiswa. Dalam hal ini, Dosen perlu meminta mahasiswa untuk menggunakan HOTS yang mencakup kemampuan menerapkan (applying), menganalisis (analyzing), mengevaluasi (evaluating), dan mencipta (creating) untuk kegiatan pembelajaran melalui: diskusi, kegiatan lapangan, praktikum, dan mahasiswa mengevaluasi sendiri keterampilan itu.

\section{METODE}

Populasi dalam penelitian ini adalah seluruh mahasiswa yang mengambil mata kuliah perencanaan pembelajaran pada program S1 pendidikan teknik mesin pada T.A. 2016/2017. Teknik pengambilan sampel pada penelitian ini adalah dengan menggunakan teknik purposive sampling dimana penelitian ini dilakukan pada seluruh populasi yang ada, yang langsung terfokus pada target. Desain penelitian ini menggunakan pendekatan eksperimen yang merupakan penelitian yang berusaha mencari dan menguji pengaruh suatu variabel atau lebih terhadap variabel yang lain. 
Penelitian ini bersifat Quasi Experiment desain faktorial 2x2. Melalui desain ini akan dibandingkan pengaruh media pembelajaran web (online) dan media pembelajaran berbasis komputer (offline) terhadap hasil belajar perencanaan pembelajaran dengan HOTS ditinjau dari sikap inovatif. Media pembelajaran berbasis web (online) dan media pembelajaran komputer (offline) diperlakukan pada kelompok eksperimen mahasiswa dengan sikap inovatif.
Analisis ini dilakukan dengan teknik Anava faktoria 2 × 2 dengan uji F. Sebelum hipotesis diuji terlebih dahulu dilakukan uji persyaratan terhadap data yang dikumpulkan yaitu dengan menggunakan uji normalitas dengan menggunakan uji Liliefors dan uji homogenitas dengan menggunakan uji $\mathrm{F}$ dan uji Bartlett. Oleh karena hipotesis ketiga dinyatakan signifikan artinya terdapat interaksi, maka uji penelitian dilanjutkan dengan menggunakan uji Scheffe.

\section{HASIL PENELITIAN}

Tabel 1. Rangkuman Data Hasil Perhitungan Analisis Deskriptif

\begin{tabular}{|c|c|c|c|c|}
\hline \multicolumn{2}{|c|}{ Sikap Inovatif } & \multicolumn{3}{c|}{ Media Pembelajaran } \\
\cline { 3 - 5 } & & Web (Online $)\left(\boldsymbol{A}_{1}\right)$ & Komputer (offline) $\left(\boldsymbol{A}_{2}\right)$ & Total \\
\hline \multirow{3}{*}{ Positif } & $\mathrm{N}$ & 13 & 14 & 27 \\
$\left(\boldsymbol{B}_{\mathbf{1}}\right)$ & $\sum X 2$ & 387 & 348 & 735 \\
& $\bar{X}$ & 11572 & 10328 & 21900 \\
& $\mathrm{~S}$ & 42,32 & 26,52 & 68,84 \\
& $\mathrm{~S}$ & 2,9 & 2,56 & 5,46 \\
\hline \multirow{3}{*}{ Negatif } & $\sum X$ & 294 & 15 & 29 \\
$\left(\boldsymbol{B}_{2}\right)$ & $\sum X 2$ & 6759 & 321 & 615 \\
& $\bar{X}$ & 29,32 & 7955 & 14714 \\
& $\mathrm{~S}$ & 3,43 & 25,53 & 54,85 \\
& $\mathrm{~N}$ & 27 & 2,57 & 6 \\
\hline \multirow{3}{*}{ Total } & $\sum X$ & 681 & 29 & 56 \\
& $\sum X 2$ & 18331 & 669 & 1350 \\
& $\bar{X}$ & 71,64 & 18283 & 36614 \\
& $\mathrm{~S}$ & 6,33 & 52,05 & 123,69 \\
& & & 5,13 & 11,46 \\
\hline
\end{tabular}

Pengujian persyaratan analisis data dilakukan pada uji normalitas dan homogenitas. Berikutnya untuk keperluan pengujian hipotesis dengan menggunakan teknik analisis varians dua jalur faktorial 2x2, uji Scheffe diperlukan untuk menghitung harga rata-rata tiap kelompok yang disajikan data hasil belajar perencanaan pembelajaran dengan HOTS pada Tabel 2.

Tabel 2. Ringkasan Perhitungan Anava Faktorial 2x2

\begin{tabular}{|c|c|c|c|c|c|c|}
\hline Sumber Varians & $\mathrm{dk}$ & $\mathrm{JK}$ & $\mathrm{RJK}$ & $\mathrm{F}_{\text {hitung }}$ & $\begin{array}{c}\mathrm{F}_{\text {tabel }} \\
0,05\end{array}$ & $\begin{array}{c}\mathrm{F}_{\text {tabel }} \\
0,01\end{array}$ \\
\hline Antar Kelompok (A) & 1 & 28,45 & 28,45 & 7,56 & & \\
\cline { 1 - 4 } Dalam Kelompok (B) & 1 & 1214,55 & 1214,55 & 198,30 & \multirow{2}{*}{4,03} & \multirow{2}{*}{7,17} \\
\hline Interaksi (AxB) & 1 & 1429,26 & 1429,26 & 238,64 & & \\
\hline Galat & 52 & 294,5 & 6,57 & & & \\
\hline Total & 55 & 2883,72 & & & & \\
\hline
\end{tabular}

Sehubungan dengan adanya interaksi maka perlu dilakukan uji lanjutan dengan uji Scheffe. Uji Scheffe dilakukan karena data untuk setiap sel adalah tidak sama, hasil pengujian dengan menggunakan uji Scheffe dapat di lihat dalam Tabel 3. 
Tabel 3. Ringkasan Hasil Pengujian Dengan Menggunakan Uji Scheffe

\begin{tabular}{|c|c|c|c|}
\hline Hipotesis Statistik & $F_{\text {hitung }}$ & $F_{\text {tabel }}$ & Keterangan \\
\hline $\mathrm{H}_{0}: \mu \mathrm{A}_{1} \mathrm{~B}_{1=}=\mathrm{A}_{2} \mathrm{~B}_{1}$ & 7,22 & 3,70 & Signifikan \\
\hline $\mathrm{H}_{0}: \mu \mathrm{A}_{1} \mathrm{~B}_{1}=\mu \mathrm{A}_{1} \mathrm{~B}_{2}$ & 13,24 & 3,70 & Signifikan \\
\hline $\mathrm{H}_{0}: \mu \mathrm{A}_{1} \mathrm{~B}_{1=}=\mu \mathrm{A}_{2} \mathrm{~B}_{2}$ & 12,91 & 3,70 & Signifikan \\
\hline $\mathrm{H}_{0}: \mu \mathrm{A}_{2} \mathrm{~B}_{1=}=\mu \mathrm{A}_{1} \mathrm{~B}_{2}$ & 9,13 & 3,70 & Signifikan \\
\hline $\mathrm{H}_{0}: \mu \mathrm{A}_{2} \mathrm{~B}_{1=}=\mu \mathrm{A}_{2} \mathrm{~B}_{2}$ & 10,66 & 3,70 & Signifikan \\
\hline $\mathrm{H}_{0}: \mu \mathrm{A}_{1} \mathrm{~B}_{2}=\mu \mathrm{A}_{2} \mathrm{~B}_{2}$ & $-1,50$ & 3,70 & Tidak Signifikan \\
\hline
\end{tabular}

\section{PEMBAHASAN}

Belajar perencanaan pengajaran dengan HOTS mahasiswa yang dibelajarkan dengan menggunakan media pembelajaran berbasis web online lebih tinggi daripada hasil belajar TIK offline mahasiswa yang dibelajarkan dengan media pembelajaran berbasis komputer, meskipun hasil belajar rata-rata siswa antara kedua kelompok tidak terlalu jauh berbeda. Dengan demikian, hasil penelitian yang ditemukan sesuai dengan pendapat yang dikemukakan Sadiman (2003) bahwa media pembelajaran mendukung kegiatan belajar, dimana fungsi atau kegunaan media antara lain: (1) membuat konkrit konsep yang abstrak, (2) membawa obyek yang berbahaya atau sukar didapat ke dalam lingkungan belajar, (3) menampilkan obyek yang terlalu besar, (4) menampilkan obyek yang tidak dapat diamati dengan mata telanjang, (5) mengamati gerakan yang terlalu cepat, (6) memungkinkan siswa berinteraksi langsung dengan lingkungannya, (7) memungkinkan kesegaran pengamatan dan persepsi bagi pengamatan belajar siswa, (8) membangkitkan motivasi belajar, (9) menyajikan informasi belajar secara konsisten dan dapat diulangi maupun disimpan menurut kebutuhan, (10) menyajikan pesan atau informasi belajar secara serempak, membatasi batasan waktu maupun ruang, dan (11) mengontrol arah maupun kecepatan belajar siswa. Pemilihan media yang tepat dalam pembelajaran akan membuat siswa semakin memahami dan mendalami isi materi pembelajaran dan berperan aktif untuk mencari dan menggali materi sehingga dapat meningkatkan hasil belajar TIK mahasiswa.

Hasil penelitian terhadap penggunaan model pembelajaran berbasis HOTS pada pembelajaran ICT sangat terkait dengan keberadaan e-learning dan multimedia interaktif. Namun dalam pelaksanaan pembelajaran ICT ada beberapa aspek yang sangat penting sebagai acuan dalam mempertimbangkan model pembelajaran berbasis HOTS. Adapun aspek tersebut adalah kemampuan mahasiswa dalam pemanfaatan ICT secara maksimal, disamping sarana dan prasarana penunjang ICT yang sesuai dengan spesifikasi perangkat yang dibutuhkan untuk kecepatan akses dalam kinerja ICT. Aspek pedagogi dan teknologi pembelajaran sangat menentukan dan terkait dalam ICT yang dimaksud adalah kesesuaian ICT terhadap teori belajar yang bersifat konstruktivisme, daya dukung terhadap pembelajaran yang berpusat pada mahasiswa, mendukung tumbuhnya keterampilan ICT, pembelajaran berbasis HOTS, meningkatkan motivasi belajar mahasiswa, kemandirian mahasiswa, serta kesesuaian web terhadap gaya belajar mahasiswa, sehingga pembelajaran ICT sangat tepat bila menggunakan model pembelajaran berbasis HOTS.

Temuan peneliti ini juga didukung oleh penelitian sebelumnya yang dilakukan oleh Putra (2008) pada siswa MTs yang menunjukkan bahwa penggunaan media interaktif berbasis komputer lebih efektif dalam meningkatkan pengetahuan dan pemahaman siswa dibandingkan dengan menggunakan media konvensional pada mata pelajaran perencanaan pengajaran dengan HOTS. Dan juga hasil penelitian menunjukkan bahwa ratarata hasil belajar perencanaan pengajaran dengan HOTS mahasiswa yang memiliki sikap inovatif positif lebih positif dibandingkan hasil belajar perencanaan pengajaran dengan HOTS mahasiswa yang memiliki sikap inovatif negatif.

Mahasiswa yang memiliki sikap inovatif yang positif akan mampu untuk menciptakan dan mengindentifikasi alternatifalternatif pemecahan masalah, imajinatif, mampu untuk melakukan berbagai hal serta lancar dalam mengemukakan gagasangagasannya. Mahasiswa dapat dengan mudah beradaptasi, menyesuaikan apa-apa yang diketahui dengan apa-apa saja yang akan dipelajarinya dalam penyelesaian pembuatan presentasi menggunakan software Ms. Office Powerpoint 2010 setelah mengikuti 
pembelajaran menggunakan media pembelajaran berbasis komputer yang telah diberikan oleh dosen. karena sikap inovatif mampu dalam memecahkan masalah-masalah dari gejala-gejala abstrak hingga kekenyataannya. Karena sikap inovatif mampu dalam memecahkan masalah-masalah dari gejala-gejala abstrak hingga kekenyataanya.

Dengan segala kemampuan yang dimilikinya, mahasiswa yang memiliki sikap inovatif positif akan mudah mencapai berbagai kompetensi dasar pada mata pelajaran perencanaan pengajaran dengan HOTS dibanding dengan mahasiswa yang memiliki sikap inovatif negatif.

Dengan demikian, hasil penelitian yang ditemukan sesuai dengan pendapat yang dikemukakan oleh Hagen (dalam Irawati, 2003) bahwa sifat-sifat yang menimbulkan kreatif akan menghasilkan kepribadian yang inovatif. Kepribadian yang inovatif adalah: (1) terbuka terhadap pengalaman baru; (2) imajinasi yang kreatif; (3) kesadaran dan tanggung jawab untuk berhasil; dan (4) punya persepsi bahwa dunia mempunyai tantangan. Respon individu terhadap perubahan merupakan keputusan terhadap inovasi, apakah individu menerima atau menolak inovasi tersebut.

Temuan peneliti ini juga didukung oleh penelitian sebelumnya yang dilakukan oleh Karitimi (2004) pada siswa SMP yang memiliki kemampuan yang bervariasi positif, sedang dan negatif dengan menggunakan media pembelajaran berbasis komputer terbukti dapat meningkatkan penguasaan konsep, keterampilan berpikir kreatif dan keterampilan proses sains siswa SMP.

Menurut Djaali (2007) sikap belajar ikut menentukan intensitas kegiatan belajar. Sikap belajar yang positif akan menimbulkan intensitas kegiatan yang lebih tinggi dibandingkan dengan sikap belajar yang negatif. Peranan sikap dalam hal ini bukan saja ikut menentukan apa yang dilihat seseorang, bagaimana juga ia melihatnya. Berdasarkan apa yang telah dikemukakan sikap belajar yang positif berkaitan erat dengan minat dan motivasi. Mahasiswa yang memiliki sikap positif akan lebih aktif dalam belajar dan dengan demikian akan memperoleh hasil yang lebih baik dibandingkan dengan mahasiswa yang sikap belajarnya negatif. Dengan demikian, hasil belajar perencanaan pengajaran dengan HOTS mahasiswa dengan media pembelajaran berbasis web online akan lebih mudah dipahami oleh mahasiswa yang memiliki sikap inovatif positif, hal ini sesuai dengan karakteristik mahasiswa yang memiliki sikap inovatif positif cenderung lebih mudah mengikuti cara belajar yang baru.

Menurut Rusman, dkk (2011: 99-100), keunggulan pembelajaran berbasis komputer adalah penerapan prinsip belajar tuntas atau mastery learning. Dalam pelaksanaan pembelajaran berbasis komputer semua mahasiswa harus dapat menyelesaikan semua pengalaman belajar yang dikemas dalam program pembelajaran berbasis komputer, baik itu berupa pemahaman materi dan tugas mengerjakan tes atau evaluasi yang harus diselesaikan dengan benar. Bila siswa salah dalam mengerjakan soal-soal latihan, maka komputer akan memberikan feedback, bahwa jawaban salah, sehingga siswa harus kembali pada uraian materi yang belum dipahaminya, setelah itu siswa dapat kembali ke soal latihan tadi untuk dikerjakan dengan benar. Dengan demikian, siswa yang memiliki kemampuan inovatif positif akan cepat selesai dalam mempelajari konten/materi pelajaran yang diprogramkan dalam pembelajaran berbasis komputer. Tapi yang memiliki sikap inovatif negatif akan mengalami kesulitan dalam mengerjakan atau memahami konten yang ada.

Pembelajaran berbasis ICT yang berlangsung tersebut bermakna luas, tidak hanya sebatas pada alat bantu, program animasi dan pemrosesan informasi, akan tetapi lebih jauh dari itu. Menurut Galarneau (2006), misalnya bagaimana pembelajaran berbasis ICT ini akan menstimulasi keterampilan abad ke-21 yaitu kemampuan berkolaborasi, HOTS, dan memperkenalkan ICT literacy dalam pembelajaran berbasis e-learning. Rancangbangun pembelajaran ICT diharapkan mahasiswa dapat mengasah pola HOTS dan menumbuhkan keterampilan ICT (ICT literacy) sesuai dengan kebijakan Inpres No 6/2001, Keppres 20/2006, Kepmendiknas No. 50/P/2007, dan amanat UNESCO. Keterampilan tersebut merupakan bagian dari keterampilan abad ke-2l, yang perlu dibekalkan pada mahasiswa untuk menunjang kebutuhan dunia kerja era global. pola interaksi yang dibangun oleh mahasiswa agar dapat memecahkan persoalan-persoalan yang disajikan dalam web interaktif secara online berbantuan akses internet.

\section{PENUTUP}


Berdasarkan hasil penelitian dan pembahasan yang dikemukakan sebelumnya, maka dapat disimpulkan bahwa: (1) hasil belajar perencanaan pengajaran dengan HOTS mahasiswa yang dibelajarkan dengan menggunakan media pembelajaran berbasis web online lebih tinggi dibandingkan dengan hasil belajar TIK off-line; (2) hasil belajar perencanaan pengajaran dengan HOTS mahasiswa yang memiliki sikap inovatif positif lebih tinggi daripada yang memiliki sikap inovatif negative; dan (3) terdapat interaksi antara media pembelajaran berbasis TIK dalam pembelajaran dengan sikap inovatif mahasiswa terhadap hasil belajar perencanaan pengajaran dengan HOTS, artinya bahwa mahasiswa yang memiliki sikap inovatif positif dengan menggunakan media pembelajaran berbasis web online maupun komputer offline akan memiliki hasil belajar perencanaan pengajaran dengan HOTS lebih tinggi dibandingkan dengan mahasiswa yang memiliki sikap inovatif negatif .

\section{DAFTAR PUSTAKA}

Arsyad, A. (2009). Media Pembelajaran. Jakarta: Rajawali Press.

Aunurrahman. Belajar dan Pembelajaran. Bandung: Alfabeta.

Briggs, Leslie, J., (1977). Intructional Design, Principle and Aplication.

Dale, E. 1969. Audiovisual Method in Teaching. New York: Dyden Press.

Gagne, R. M. (1985). The Condition of Learning and Theory of Instruction, $4^{\text {th }}$ ed. New York: CBS College Publishing.

Gagne, R.M., Briggs, L.J \& Wager, W.W. (1988). Principles of Instruction Design, $3^{\text {rd }}$ edition. New York: Saunders College Publishing.

Hall, R.H. Usabiliti Assessment of a Web-Based Learning System for Teaching Web Development: A Progress Scaffolding Approach, 2003. http://-www.umr.edu. Accessed 11 Agustus 2012.

Heinich, R., Molenda, M., Russell, J. D., \& Smaldino, S.E. (2002). Instructional Media and Technology for Learning, 7th edition. New Jersey: Prentice Hall, Inc.

Heinich, R., Molenda, M., Russell, J. D., \& Smaldino, S.E. (2002). Instructional Media and Technology for Learning, $7^{\text {th }}$ edition. New Jersey: Prentice Hall, Inc.
Joyce, B., dan Weil, M., (2009). Models of Teaching. Yogyakarta: Pustaka Pelajar.

Joyce, B., dan Weil, M., (2009). Models of Teaching. Yogyakarta: Pustaka Pelajar.

Latuheru, D. John, M.P (1998). Media Pembelajaran dalam Proses Belajar

Lucas, Henry. C. (2000). Analisis, Disain dan Implementasi Sistem Informasi.

Mayer, Ricard, E. (2009). Multimedia Learning (Second Edition). United State Of America: Cambridge University Press.

Munadi, Y. (2008). Media Pembelajaran Sebuah Pendekatan Baru. Jakarta: Gaung Persada Press.

Munir. (2008). Kurikulum Berbasis TIK. SPs Universitas Pendidikan Indonesia.

Riduwan. 2007. Metode dan Teknik Menyusun Proposal Penelitian. Bandung: ALFABETA.

Rusman, dkk., (2011). Pembelajaran Berbasis Teknologi Informasi dan Komunikasi: Mengembangkan Profesionalisme Guru. Jakarta: PT Raja Grafindo Persada.

Rusman, dkk., (2011). Pembelajaran Berbasis Teknologi Informasi dan Komunikasi: Mengembangkan Profesionalisme Guru. Jakarta: PT Raja Grafindo Persada.

Rusman. (2011). Model-model Pembelajaran: Mengembangkan Profesionalisme Guru. Jakarta: PT. Rajawali Pers.

Sadiman, A.S. (1986). Media Pendidikan: Pengeratian Pengembangan, dan

Sadiman, A.S. (1986). Media Pendidikan: Pengeratian Pengembangan, dan

Sardiman. (2010). Interaksi dan Motivasi Belajar Mengajar. Jakarta: Penerbit Grafindo.

Siemen, G. (2005). Connectivisme: A learning theory for digital age.International

Soekartawi. (2003). E-Learning di Indonesia dan Prospeknya di Masa Mendatang. Makalah disampaikan pada Seminar Nasional E-Learning Perlu E-Library di Universitas Kristen Petra Surabaya.

Utami, B et al. (2011). Penerapan Pendekatan Konstruktivisme Melalui Model Pembelajaran Think Pair Share (TPS) dalam Kegiatan Lesson Study untuk Meningkatkan Kualitas Proses dan Hasil Belajar Strategi Belajar-Mengajar. Jurnal Inovasi Pendidikan Jilid 12 Nomor 1 p 1 -18 .

Wallington, C.J. (1996). Media Production: Production of Still Media. Plomp, T., \& Ely, D.P. (Eds.): International 
Jurnal Teknologi Informasi dan Komunikasi dalam Pendidikan, Vol. 4 No. 2 Desember 2017, p-ISSN: 2355-4983; e-ISSN: 2407-7488

Encyclopedia of Educational

Technology, $2^{\text {nd }}$ edition. New York:
Elsevier Science, Inc. 